\title{
Improving the nutritional status of food-insecure women: first, let them eat what they like
}

\author{
Lynn Mclntyre ${ }^{1, *}$, Valerie Tarasuk ${ }^{2}$ and Tony Jinguang $\mathrm{Li}^{3}$ \\ 'Department of Community Health Sciences, Faculty of Medicine, University of Calgary, Heritage Medical Research \\ Building Room G021, 3330 Hospital Drive NW, Calgary, Alberta, Canada, T2N 4N1: ${ }^{2}$ Department of Nutritional \\ Sciences, Faculty of Medicine, University of Toronto, Toronto, Ontario, Canada, M5S 1A8: ${ }^{3}$ Department of Statistics, \\ Purdue University, West Lafayette, IN 47906, USA
}

Submitted 11 September 2006: Accepted 19 January 2007: First published online 15 March 2007

\begin{abstract}
Objective: To determine the extent to which identified nutrient inadequacies in the dietary intakes of a sample of food-insecure women could be ameliorated by increasing their access to the 'healthy' foods they typically eat.

Design: Merged datasets of 226 food-insecure women who provided at least three 24-hour dietary intake recalls over the course of a month. Dietary modelling, with energy adjustment for severe food insecurity, explored the effect of adding a serving of the woman's own, and the group's typically chosen, nutrient-rich foods on the estimated prevalence of nutrient inadequacy.

Setting and subjects: One study included participants residing in 22 diverse community clusters from the Atlantic Provinces of Canada, and the second study included food bank attendees in Toronto, Ontario, Canada. Of the 226 participants, 78\% lived alone with their children.

Results: While nutritional vulnerability remained after modelling, adding a single serving of either typically chosen 'healthy' foods from women's own diets or healthy food choices normative to the population reduced the prevalence of inadequacy by at least half for most nutrients. Correction for energy deficits resulting from severe food insecurity contributed a mean additional 20\% improvement in nutrient intakes.

Conclusions: Food-insecure women would sustain substantive nutritional gains if they had greater access to their personal healthy food preferences and if the dietary compromises associated with severe food insecurity were abated. Increased resources to access such choices should be a priority.
\end{abstract}

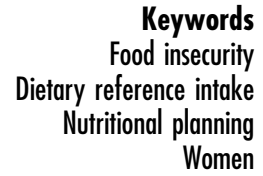

Keywords reference intake Women
The nutritional vulnerability of very-low-income and foodinsecure women in Canada, particularly lone mothers, has been well documented ${ }^{1-7}$. Qualitative studies have demonstrated a lack of affordability of nutritious food and intra-household distribution of food that favours children's consumption of a healthier diet over mothers ${ }^{8-10}$. Dietary intake studies have demonstrated high levels of nutrient inadequacy among food-insecure women ${ }^{4,5}$.

A common response to food insecurity in Canada has been the provision of free or subsidised food through food banks or targeted meal programmes. Such programmes operate through community-based initiatives that rely upon charitable donations and delivery methods ${ }^{11-14}$. 'Healthy eating' initiatives have used health promotion and community development strategies in this population to encourage healthier food purchasing and food preparation skills (e.g. community kitchens) ${ }^{15-21}$. Other community food security strategies have focused on alternative methods of food acquisition such as community gardens, field-to-table programmes and 'Good Food Boxes' ${ }^{22,23}$. While all programmes acknowledge the need for families and individuals at risk of food insecurity to have increased access to affordable, nutritious food, there is typically limited understanding of how much food or what kinds of food are most needed.

With the recent publication of a report describing the application of Dietary Reference Intakes (DRIs) for use in dietary planning ${ }^{24}$, a conceptual framework and an analytic process have been described to plan for dietary intakes at group level with the goal of achieving a distribution of usual intakes that minimises the prevalence of nutrient inadequacy or excess. While the report furnishes the conceptual foundation for the development of targeted, food-based interventions to reduce nutritional risk among food-insecure groups, empirical applications are needed to appraise the utility of the proposed approach. We applied dietary modelling methodology based upon the DRI dietary planning framework ${ }^{24}$ to a combined sample of food-insecure women in order to 
examine the potential for different food interventions to improve the nutrient adequacy of intakes in this vulnerable population. In identifying food-based interventions to test, our purpose was not to model ideal dietary intakes but to examine how increased consumption of affordable commodities already chosen as food preferences by food-insecure women would improve nutritional intake.

\section{Methods}

The study utilised dietary intake data collected from two independent samples of low-income, food-insecure women with children: one examining low-income lone mothers in Atlantic Canada ${ }^{3,4}$ and a second that included women attending food banks in Toronto ${ }^{5,6,25}$. The original results of these studies have been published previously $^{3-6,25}$.

Table $1^{26-29}$ presents a detailed comparison of the two study designs. The studies had similar sample sizes, and each collected multiple 24-hour food recalls over the course of one month and 30-day measures of food insecurity from unique, highly vulnerable populations that were geographically dispersed and ethnically diverse. Thus the combined sample permitted greater generalisability than each study would have achieved alone. The larger combined sample size also permitted extensive dietary modelling.

The combined sample constituted 289 women (153 from the Toronto study and 136 from the Atlantic study) for whom there were complete food insecurity responses and who were not pregnant or lactating. For purposes of this analysis, our final sample size was 226; we excluded 55 respondents from the Atlantic study because of a previously documented interviewer bias that led to underreporting of dietary intake (on previous analyses, there was no other systematic bias introduced by exclusion of this group other than the allocation of interviewer ${ }^{4}$ ) and eight Toronto study respondents whose dietary recalls fell outside the one-month period of food security measurement.

\section{Procedures for combined analysis}

Prior to dietary assessment and modelling, we needed to ensure comparability in the dietary intake data from the two studies and create a common metric from the two food insecurity measures. Although the food composition databases used in the original studies were both based on the Canadian Nutrient Data File, to remove any potential bias in the nutrient intake estimates related to differences in the databases, we re-entered the recall data of the 81 women in the Atlantic study into CANDI (Canadian Dietary Information System). Because this database does not compute vitamin A intakes in retinol activity equivalents, the unit of measurement for current requirements ${ }^{30}$, values for this nutrient were drawn from US food composition tables ${ }^{31,32}$. Women's reported food intakes were expressed as servings per day according to the five broad groups in Canada's Food Guide to Healthy Eating: grain products; vegetables and fruit (including juices); milk products; meat, fish, poultry, eggs and alternatives (i.e. nuts, seeds, legumes); and other foods ${ }^{31}$.

The two studies used different instruments to assess food insecurity: the Radimer/Cornell questionnaire ${ }^{26}$ in the Atlantic study and the US Department of Agriculture's (USDA) Food Security Module ${ }^{29}$ in the Toronto study. These instruments are conceptually similar and share some individual items, and both instruments were applied to capture severity of food insecurity over a 30-day period. With the assistance of Mark Nord of the Economic Research Service of the USDA, a common scale of severity for food insecurity was devised. Nord applied the Rasch measurement model ${ }^{33}$ to assess food security question sets and identify thresholds that are comparable to those of the Food Security Module. This resulted in common 'metrics' for adult and child food security status, across which all of our participants could be scaled. A detailed description of these procedures is available elsewhere ${ }^{34,35}$.

Using the dichotomous variable developed to differentiate women reporting food insecurity with and without evidence of hunger (note that, in 2006, the nomenclature was revised to very low and low food security, respectively; http://www.ers.usda.gov/Briefing/ FoodSecurity/labels.htm), we applied analysis of variance to compare reported intakes of food groups, energy, nutrients and nutrients per MJ ('nutrient densities') among women by food insecurity status. We also re-ran these analyses controlling for other behavioural and sociodemographic characteristics found to be significantly associated with intakes in this sample. Box-Cox transformations were applied to the intake data prior to these analyses to ensure that the dependent variables approximated normal distributions.

We estimated the distributions of usual energy and nutrient intakes for the entire sample and assessed the apparent adequacy of women's micronutrient intakes following the methods outlined in the DRI report on assessment $^{36}$. The observed distribution of intakes for each nutrient of interest was adjusted for within-person variance to estimate the distribution of usual intakes using SIDE (Software for Intake Distribution Estimation) $)^{37}$. Because preliminary analyses revealed no significant effects of interview method (face-to-face vs. telephone interview in the Atlantic study), day of the week and interview sequence on estimated energy and nutrient intakes, no adjustments were made for these variables. In addition, because very few women in these studies consumed supplements, and virtually none did so on a regular basis ${ }^{6,38}$, we considered nutrient intake from food sources only in these analyses. To satisfy the SIDE requirement for a perfectly balanced sample of days per person, for the Atlantic study sample, the first recall and 
Table 1 Design characteristics of the Atlantic Provinces and Toronto studies

\begin{tabular}{|c|c|c|}
\hline & Atlantic Provinces Study & Toronto study \\
\hline & $\begin{array}{l}\text { Hungry Mothers of Barely Fed Children (NHRDP } \\
\text { Project No. 6603-1550-002) }\end{array}$ & $\begin{array}{l}\text { Nutritional Vulnerability and Food Insecurity among } \\
\text { Women in Families Using Food Banks (NHRDP } \\
\text { Project No. 6606-5609-201) }\end{array}$ \\
\hline Objectives & $\begin{array}{l}\text { To document the occurrence and extent of food } \\
\text { insecurity among low-income mothers in Atlantic } \\
\text { Canada in relation to their children }\end{array}$ & $\begin{array}{l}\text { To assess the food insecurity and nutritional } \\
\text { vulnerability of women in families who seek emergency } \\
\text { food relief from food banks in Metropolitan Toronto }\end{array}$ \\
\hline Sample & $\begin{array}{l}141 \text { women ( } 12 \text { pregnant or lactating), aged } \\
19-46 \text { years, all with at least two children } \\
<14 \text { years whose income was below the low } \\
\text { income cut-off }\end{array}$ & $\begin{array}{l}153 \text { non-pregnant women, aged } 19-48 \text { years, all with } \\
\text { at least one child }<15 \text { years }\end{array}$ \\
\hline Recruitment & $\begin{array}{l}\text { Participants were recruited through parent resource } \\
\text { centres, public health staff, community workers, } \\
\text { volunteers and other respondents in over } 12 \\
\text { communities in the four Atlantic provinces }\end{array}$ & $\begin{array}{l}\text { Women were recruited on a first-come, first-served basis } \\
\text { when they came to seek food assistance from one of } \\
\text { a stratified random sample of } 21 \text { of the } 77 \text { emergency } \\
\text { food hamper programmes in Toronto }\end{array}$ \\
\hline Data collection & February 1999-February 2000 & May 1996-April 1997 \\
\hline Dietary intake measures & $\begin{array}{l}\text { One in-person 24-hour dietary intake recall and } \\
\text { three telephone-administered } 24 \text {-hour dietary } \\
\text { intake recalls, collected in each of four } \\
\text { consecutive weeks, including at least one } \\
\text { weekend day }\end{array}$ & $\begin{array}{l}\text { Three in-person 24-hour dietary intake recalls, collected on } \\
\text { non-consecutive days and different days of the week, } \\
\text { within a 31-day window for } 95 \% \text { of participants }(n=145)\end{array}$ \\
\hline $\begin{array}{l}\text { Software used for analysis } \\
\text { of food composition }\end{array}$ & $\begin{array}{l}\text { FoodSmart }{ }^{\circledR} \text { Millennium Professional Edition } \\
\text { Program, based on the Canadian Nutrient File }\end{array}$ & $\begin{array}{l}1996 \text { version of the Canadian Dietary Information } \\
\text { (CANDI) System, based on the Canadian Nutrient File }\end{array}$ \\
\hline $\begin{array}{l}\text { Food security measures } \\
\text { and scaling }\end{array}$ & $\begin{array}{l}\text { Radimer/Cornell Questionnaire - a 13-item } \\
\text { instrument, consisting of four subscales to } \\
\text { differentiate household food insecurity, } \\
\text { mother's food insecurity, mother's hunger } \\
\text { and child's hunger }{ }^{26-28} \text {. The questionnaire } \\
\text { was administered in its entirety in Interview } \\
1 \text { to assess food insecurity over the past year, } \\
\text { and modified versions were administered in } \\
\text { Interviews } 2,3 \text { and } 4 \text { to detect changes across weeks }\end{array}$ & $\begin{array}{l}\text { USDA Food Security Module - an 18-item, fully calibrated, } \\
\text { unidimensional scale of severity of household food } \\
\text { insecurity }{ }^{29} \text {. The module was administered, with the } \\
\text { omission of one item, in the third interview to assess } \\
\text { food insecurity over the previous } 12 \text { months and } 30 \text { days }\end{array}$ \\
\hline
\end{tabular}

NHRDP - National Health Research and Development Program; USDA - US Department of Agriculture.

two randomly selected follow-up recalls (instead of all four recall days) were used.

Nutrient adequacy was assessed by comparing the estimated distribution of usual intakes with current requirement estimates ${ }^{30,36,39-41}$. For nutrients with defined, symmetrical requirement distributions, prevalence of inadequacy was estimated as the proportion of usual intakes below the Estimated Average Requirement (i.e. the 'EAR cut-point method'). The skewed nature of the requirement distribution for iron precludes application of the cut-point method for this nutrient; thus, we applied a full probability approach to assess the prevalence of inadequacy for iron ${ }^{30}$. Iron requirements were also corrected for oral contraceptives use, assuming a $17 \%$ prevalence of utilisation $^{30}$. For calcium, the group mean and median intakes were interpreted relative to the estimated Adequate Intake (AI) ${ }^{36,39}$. The adequacy of protein intakes was not assessed because body weight was not measured in the Atlantic sample. Folate and vitamin D were also omitted from these analyses because we lacked current, comprehensive, food composition values for these nutrients.

\section{Dietary modelling metbodology}

As outlined in the DRI planning report ${ }^{24}$, the goal of dietary planning for groups is defined in terms of achieving a distribution of usual intakes that minimises the prevalence of nutrient inadequacy or excess. There are four steps in the planning of diets for a homogeneous group: setting nutritional goals; estimating the usual distribution of intakes; menu planning; and assessment. The planning process is iterative, with the end goal typically being to achieve a prevalence of inadequacy of $2-3 \%$. As a novel strategy to inform policy development, we applied the DRI dietary planning and assessment framework to test for expected effects of dietary intervention in a nutritionally vulnerable free-living population. Specifically, we modelled the effects of various food-based interventions on women experiencing various levels of food insecurity to identify changes in intake that would reduce the prevalence of inadequacy of all nutrients assessed, and achieve a median intake for the population equal to the AI for calcium. An analysis of upper tolerable intake levels was unnecessary in this nutritionally deprived population.

To examine the impact of different food-based interventions on the nutrient adequacy of the intakes of women in our sample, we systematically added particular nutrient-rich foods to participants' food records. Food additions were selected from three categories: milk, fruit and vegetables, because of prior research suggesting that the purchase of these food groups is most likely to be 
compromised among Canadian households facing economic constraints ${ }^{42,43}$. With each addition, the distribution of usual nutrient intakes was re-estimated and the prevalence of nutrient inadequacy was re-calculated.

Two methods were employed to select nutrient-rich food additions:

- Method A - adding a serving of the woman's own typically chosen foods.

- Method B - adding a serving of the foods typically chosen by the sample as a whole.

Food preferences were computed for each woman and again for the whole sample by examining the food by food group category that contributed the most energy to each woman's total intake over three recall days. The top three fruits were fruit juice, bananas and apples. The top three vegetables were potatoes, lettuce and leafy greens, and tomatoes. The top three milk products were fluid milk with $2 \%$ butterfat, whole milk, and cheese with more than $25 \%$ butterfat. For Method B, the dietary plan in which we added commonly accepted foods to the diet, we added Fruit: 1 serving of orange juice from concentrate; Vegetables: 1 serving of potatoes, boiled, cooked, without skin; and Milk: 1 serving of fluid milk, partly skimmed, with $2 \%$ butterfat.

Using Method A, one could see a recommendation that would encourage increased consumption of food-insecure women's favourite 'healthy' foods as a recommendation for dietary improvement, and in Method B, one could recommend greater access to commonly consumed, nutritious foods for the population. We limited the additions to one serving of food per group in order to limit the increase in energy intake and to represent a modest and likely achievable increase in consumption of previously chosen foods. We did not conduct dietary modelling on foods that would ideally reduce the prevalence of inadequacy as we did not consider this a realistic policy approach, nor one that would necessarily be complied with by women who would lack resources to purchase these foods or be reluctant to consume them because of their own food likes and dislikes.

Using fruit as an example, dietary modelling for Method A used the following steps:

1. For the recall day when a woman consumed fruit (for example, 1/2 cup of orange juice and 1 apple), we added one more fruit serving (i.e. in this case, we would add $<1$ apple plus $<1 / 2$ cup juice to equal 1 serving).

2. For the recall day when a woman had no fruit intake but when she had consumed fruit on at least one other recall day, we added 1 serving of 'woman's averaged fruit' (one that contained the fruit consumed by the woman amounting to 1 serving but weighted to reflect whatever mixture of fruit she had).
3. For those who had no fruit intake during any recall day, we added 1 serving of the 'group's averaged fruit' amounting to 1 serving.

We initially used the women's reported food intakes over three days as the baseline for modelling interventions, but because the observed intakes of some women in this study were likely compromised by the acute effects of severe food insecurity (i.e. food insecurity with hunger), we also conducted the dietary modelling with a correction for food insecurity status that adjusted the intakes of women reporting hunger to bring their total energy intakes, and to a lesser extent their total food group intakes, on average, up to the same level as women not reporting hunger. This adjustment was accomplished by increasing the amounts of fruit, vegetables, milk products, and meat and meat alternatives on the 24-hour recalls of each woman reporting hunger incrementally until the mean energy intake of women in this group equalled that of the women not reporting hunger. The adjustment removed all significant differences in energy and nutrient intakes except for vitamin A, which remained significantly lower among the 'with hunger' group. The adjustment results also supported our decision to exclude grain products and 'other' foods from the incremental adjustment given the lower nutrient density of these food categories. Thus, for both methods, we assessed the prevalence of inadequacy at the population level by doing such intervention on our original data (3-day intakes) as well as on the data that were adjusted for level of food insecurity.

\section{Results}

The characteristics of the analytic sample are presented in Table 2. On average, the combined sample of women had intakes below recommended levels for all food groups except meat and meat alternatives (Table 3). When their food intake patterns were compared, women who were food-insecure with hunger had systematically lower intakes of fruits and vegetables, and, depending upon whether results were adjusted or not for covariates, demonstrated varying levels of significance for the other food groups (Table 4). Women who were food-insecure with hunger also had systematically lower intakes of energy and most nutrients with or without covariate adjustment (Table 4). When women's nutrient intakes were expressed as ratios of total energy, no differences were observed except for vitamin A per MJ, which was significantly lower among those experiencing food insecurity with hunger (data not shown).

Prevalences of inadequacy in excess of $25 \%$ were observed for iron, magnesium, thiamin, vitamin $\mathrm{B}_{12}$, vitamin $\mathrm{A}$, vitamin $\mathrm{C}$, vitamin $\mathrm{B}_{6}$ and zinc (Table 5). Adjustments to 'remove' the compromising effects of food insecurity with hunger on the reported food intakes of 92 women in the sample served to diminish the prevalence of 
Table 2 Characteristics of joint study women $(n=226)$

\begin{tabular}{lr}
\hline & \\
& \\
& $n(\%)$ \\
\hline Age of mothers (years) & \\
$19-24$ & $35(15.5)$ \\
$25-29$ & $51(22.6)$ \\
$30-34$ & $67(29.7)$ \\
$35-39$ & $40(17.7)$ \\
$40-44$ & $20(8.9)$ \\
$45-49$ & $13(5.8)$ \\
Self-identified cultural background & \\
White & $125(55.3)$ \\
African Canadian & $48(21.2)$ \\
Racially visible immigrant & $30(13.3)$ \\
Aboriginal & $10(4.4)$ \\
Other/not stated & $13(5.8)$ \\
Educational status & \\
Elementary or less & $21(9.3)$ \\
Some high school & $66(29.2)$ \\
High school graduation & $57(25.2)$ \\
Some post-secondary & $68(30.1)$ \\
Degree or more & $14(6.2)$ \\
All income sources & \\
Child tax credit & $193(85.4)$ \\
Social assistance/welfare & $147(65.0)$ \\
Wages & $46(20.4)$ \\
Child support & $33(14.6)$ \\
Employment insurance & $9(4.0)$ \\
Other income & $16(7.1)$ \\
Number of children in household & \\
1 & $42(18.6)$ \\
2 & $112(49.6)$ \\
3 & $47(20.8)$ \\
$\geq$ & $25(11.1)$ \\
Age of oldest child in household (years) & \\
$0-4$ & $69(30.5)$ \\
$5-9$ & $126(55.8)$ \\
Smoking status 10 & $31(13.7)$ \\
Daily & \\
Occasionally & $134(59.3)$ \\
Never & $9(4.0)$ \\
\hline & $83(36.7)$ \\
\hline & \\
& \\
& \\
&
\end{tabular}

inadequacy for all nutrients examined, resulting in an overall mean improvement of $17.1 \%$ in prevalence rates (median: 16.3\%), without any other dietary intervention.

Method A, the first modelling plan that added women's typically chosen foods by food group, substituted the group's preferred food in the model if the consumption from that food group was already zero. In fact, zero consumption over all dietary recalls occurred in the case of fruit for $76(33.6 \%)$ women, for dairy in seven (3.1\%) women, and for two (0.8\%) women in the case of vegetables.

Tables 6 and 7 present the results of dietary modelling using both methods with and without adjustment for food insecurity status. The population began the dietary modelling exercise with a high prevalence of inadequacy and a suboptimal median intake of calcium. For each model, only riboflavin and niacin were able to meet the dietary planning goal of $2-3 \%$ prevalence of inadequacy. Method $\mathrm{B}$ also met that goal for vitamin $\mathrm{B}_{12}$. Adding a single daily serving of milk products using Method A or B shifted the distribution of calcium intakes markedly, but the median intake reached the AI only for Method A, and then only when intakes were adjusted for food insecurity status.

Method A led to better results than Method B for vitamin A, zinc, iron, magnesium and calcium. The reverse was true for thiamin and vitamin C. Both methods succeeded in reducing the prevalence of inadequacy by at least $50 \%$ for almost all nutrients, but serious inadequacies remained for iron (non-users of oral contraceptives) and magnesium. The addition of a daily serving of milk to women's diets led to at least a $75 \%$ reduction in the prevalence of inadequacy for niacin, riboflavin and vitamin $\mathrm{B}_{12}$, and marked improvement in the apparent adequacy of calcium intakes. In order to achieve nutritional gains of at least $50 \%$ reduction in the prevalence of inadequacy for magnesium, thiamin, vitamin $\mathrm{A}$ and vitamin $\mathrm{B}_{6}$, however, a single food group addition was insufficient and women required a serving from each of the fruit, vegetable and milk categories. This pattern of results remained when energy adjustments were made to the dietary intakes of women reporting food insecurity with hunger.

Adjustment for food insecurity with hunger increased energy intake by $284 \mathrm{~kJ}$ to a mean of $7536 \mathrm{~kJ}$. With the addition of a single milk serving, energy consumption after food insecurity adjustment increased energy intake by $268 \mathrm{~kJ}$ for Method A. These two additions would raise women's intakes to $7804 \mathrm{~kJ}$, just below the average daily energy consumption of $7825 \mathrm{~kJ}$ ( $95 \%$ confidence interval: $7683-8219 \mathrm{~kJ})$ for Canadian women aged 20-39 years recently reported in a national survey ${ }^{44}$. Other dietary

Table 3 Food group intakes (servings day ${ }^{-1}$ ) of joint study women $(n=226)$

\begin{tabular}{lccc}
\hline Food group & Mean \pm SD & Minimum-maximum & Recommended $^{*}$ \\
\hline Grains & $3.99 \pm 2.14$ & $0.48-10.94$ & $5-12$ \\
Milk products & $1.01 \pm 0.98$ & $0-6.17$ & $2-4$ \\
Fruit and vegetables including potatoes & $3.81 \pm 2.61$ & $0-16.06$ & $5-10$ \\
Fruit and vegetables excluding potatoes & $2.97 \pm 2.37$ & $0-14$ & \\
Fruit & $1.16 \pm 1.42$ & $0-7.07$ & \\
Vegetables excluding potatoes & $1.80 \pm 1.58$ & $0-10.51$ & \\
$\quad$ Potatoes & $0.84 \pm 0.85$ & $0-4.46$ & $2-3$ \\
Meat and alternatives & $2.16 \pm 1.15$ & $0-6.57$ & \\
$\quad$ Meat & $2.04 \pm 1.14$ & $0-6.38$ & \\
Meat alternatives & $0.13 \pm 0.23$ & $0-1.15$ & \\
\hline
\end{tabular}

SD - standard deviation.

*From Canada's Food Guide to Healthy Eating ${ }^{31}$. 
Table 4 Comparison of food, energy and nutrient intakes of women reporting food insecurity with hunger and those not reporting hunger $(n=226)$

\begin{tabular}{|c|c|c|c|c|}
\hline \multirow[b]{2}{*}{ Intake per day } & \multicolumn{2}{|c|}{ Adult food insecurity, mean \pm SD } & \multirow[b]{2}{*}{$\begin{array}{c}F \text {-value } \\
(P \text {-value }), \text { unadjusted }\end{array}$} & \multirow[b]{2}{*}{$\begin{array}{c}F \text {-value } \\
(P \text {-value })^{*}\end{array}$} \\
\hline & $\begin{array}{l}\text { No hunger } \\
(n=134)\end{array}$ & $\begin{array}{l}\text { Hunger } \\
(n=92)\end{array}$ & & \\
\hline Grains (servings) & $4.57 \pm 2.37$ & $3.90 \pm 2.06$ & $4.61(0.0328)$ & $3.65(0.0578)$ \\
\hline Milk products (servings) & $1.17 \pm 1.22$ & $0.81 \pm 0.69$ & $7.84(0.0056)$ & $3.17(0.0762)$ \\
\hline Fruit and vegetables, incl. potatoes (servings) & $3.77 \pm 2.55$ & $2.86 \pm 2.13$ & $8.08(0.0049)$ & 7.35 (0.0073) \\
\hline Meat and alternatives (servings) & $2.07 \pm 1.12$ & $1.86 \pm 1.09$ & $2.45(0.1189)$ & $4.28(0.0398)$ \\
\hline Energy (kJ) & $7476.62 \pm 3247.41$ & $6340.95 \pm 2550.68$ & $7.12(0.0082)$ & $4.39(0.0374)$ \\
\hline Protein $(\mathrm{g})$ & $67.22 \pm 29.27$ & $56.09 \pm 22.78$ & $8.53(0.0039)$ & $4.33(0.0386)$ \\
\hline Calcium (mg) & $624.80 \pm 403.60$ & $495.28 \pm 286.63$ & $6.98(0.0089)$ & $3.90(0.0497)$ \\
\hline Zinc (mg) & $9.02 \pm 4.40$ & $7.42 \pm 3.29$ & $7.44(0.0069)$ & $2.35(0.1263)$ \\
\hline Riboflavin (mg) & $1.43 \pm 0.80$ & $1.16 \pm 0.51$ & $8.24(0.0045)$ & $3.91(0.0492)$ \\
\hline Niacin (mg) & $28.12 \pm 11.79$ & $23.22 \pm 8.96$ & $10.93(0.0015)$ & $4.88(0.0282)$ \\
\hline Iron (mg) & $10.93 \pm 5.70$ & $9.30 \pm 3.93$ & $4.91(0.0277)$ & $1.59(0.2082)$ \\
\hline Vitamin C (mg) & $99.95 \pm 81.86$ & $77.91 \pm 63.74$ & $4.32(0.0389)$ & $4.25(0.0405)$ \\
\hline Magnesium (mg) & $228.25 \pm 102.88$ & $196.28 \pm 84.23$ & $5.70(0.0178)$ & $5.02(0.0261)$ \\
\hline Thiamin $(\mathrm{mg})$ & $1.10 \pm 0.52$ & $0.92 \pm 0.46$ & $9.22(0.0027)$ & $4.67(0.0317)$ \\
\hline Vitamin $B_{6}(\mathrm{mg})$ & $1.36 \pm 0.65$ & $1.09 \pm 0.47$ & $10.59(0.0013)$ & $7.67(0.0061)$ \\
\hline Vitamin $B_{12}(\mu \mathrm{g})$ & $4.19 \pm 6.11$ & $2.76 \pm 2.39$ & $6.30(0.0128)$ & $1.29(0.2575)$ \\
\hline Vitamin A (RAE) & $743.04 \pm 945.89$ & $432.21 \pm 389.69$ & $17.45(0.0001)$ & $13.48(0.0003)$ \\
\hline
\end{tabular}

SD - standard deviation; RAE - retinol activity equivalents.

${ }^{*}$ F-test of difference by food security status, derived from a general linear model, using transformed intake data and controlling for study (Atlantic vs. Toronto), education (post-secondary or degree), age of oldest child $\leq 4$ years, daily smoker, presence of employment income, and number of children ( $\geq 3$ ).

modelling increased mean energy intake by between 1071 and $1533 \mathrm{~kJ}$ per day depending upon the model, food group servings added and food insecurity adjustment. Method B had a lower increase in energy intake.

Table 8 summarises the highest achievable nutritional gains that would accrue from Method A that added women's typically chosen foods and after their food insecurity with hunger was abated. Whereas most nutrient modelling results fell short of the dietary planning goal of $2-3 \%$ prevalence of inadequacy, except for persistently high values for iron in non-users of oral contraceptives and magnesium, resultant values for other nutrients were generally less than $15 \%$ prevalence of inadequacy after reductions of between 53 and 81\% from baseline.

\section{Discussion}

Our application of the DRI planning framework to a freeliving, food-insecure population provides insight into the kinds of dietary changes required to lessen nutritional vulnerability in this group. Both the assessment of the effects of dietary intervention, in our case dietary modelling with respondents' typically chosen foods, and the nutritional implications of the 'intervention' provide sound empirical policy evidence that can be used to improve the nutritional status of a vulnerable population.

Although the interventions modelled here were insufficient to achieve the planning goal of a $2-3 \%$ prevalence of inadequacy for almost all nutrients considered, dietary modelling including both typically chosen 'healthy' foods known to be consumed by foodinsecure individuals and by the group as a whole had a strong impact in reducing the prevalence of inadequacy for most nutrients by more than $50 \%$ and bringing median calcium intake close to an optimal level. The impact of these interventions was further improved when adjustments were made to 'remove' the apparent suppression of intake associated with severe food insecurity among some women in the sample.

Corrections of lower energy consumption attributed to food insecurity with hunger and addition of a serving of women's preferred milk choice should have limited implications for changes in body weight, bringing the respondent population's energy intake to that of a comparable food-secure population of women. In contrast, the consumption of three additional servings per day without compensatory reduction in the intake of less nutrient-rich foods or increased activity could lead to weight gain and possibly contribute to obesity. We doubt that such a change in intake would occur without a correction in overall consumption.

We recognise that efforts to improve diet quality among food-insecure women beyond access to their typically chosen 'healthy' foods would still be required in order to reduce the prevalence of inadequacy for all nutrients to $2-3 \%$. These efforts would likely be in line with dietary messages directed at the general adult female population, where concerns about suboptimal intakes of nutrients like magnesium, calcium and iron are commonplace ${ }^{30,39}$.

We posit that increased access to fruit, vegetables and milk would yield significant public health nutrition gains in food-insecure women without the need for other 'healthy eating' interventions such as nutrition education, culinary skills, and food purchase strategies. However, increasing the consumption of these commodities is not without cost. For example, an additional serving of milk 
per day for a woman living in Nova Scotia, Canada (7.51 or $250 \mathrm{oz}$ ) would increase her food budget by \$Can 11.25 (March 2006) per month from a per person monthly food budget of \$Can 95.40 ( \pm \$Can 31.60) (grocery expenditure data from the Atlantic study). These costs would be even greater if women were to add one serving per day from each food group to their diets.

There are numerous studies demonstrating that the cost of healthy eating in Canada is far below the current rates received by families through income assistance or minimum wage employment ${ }^{45,46}$. For example, a family led by a lone female parent with two children who worked full-time at the April 2006 minimum wage rate in Nova Scotia would need an extra \$Can 385.00 per month to cover the costs of the National Nutritious Food Basket for its members ${ }^{47}$. We have shown that increased resources in low-income families are indeed directed towards food purchases, including healthier foods ${ }^{3,4}$. However, in the context of severe economic constraints, we do not know that women would increase their purchase and consumption of fruit, vegetables and milk if they had additional resources for food. The additional resources might be allocated to improve the diets of their children ${ }^{4,10}$.

Our results identify, for this population, commonly consumed nutritious foods that would gain ready acceptance as part of community food security offerings. Unfortunately though, this list would not support community food insecurity initiatives that promote locally grown produce because it relies upon foods that are not locally available or that may be available only seasonally (e.g. orange juice, lettuce, bananas). Income would be essential to purchase these foods from grocery outlets rather than acquire them through local production initiatives. The volume of food required (e.g. 30 bananas per month for an individual) also exceeds the current capacity of community food sources such as food banks, 'Good Food Boxes' and community gardens to meet requirements.

As an empirical example of the methodology proposed for planning dietary intakes for groups ${ }^{24}$, our study highlights a number of limitations inherent in this approach. Although we tried to be as realistic as possible in selecting foods to be added to women's diets, our modelling assumes that the added foods will be consumed every day, and that they will constitute a net increase in energy and nutrient intake, rather than displacing other foods in the women's diets. With these assumptions, had we continued to add servings of 'healthy' foods incrementally or had we modelled additional servings from the grain group until an acceptably low prevalence of nutrient inadequacy was achieved in this sample, we would have increased women's total energy intakes substantially, drawing into question the healthfulness of the overall diets we were modelling. It is also important to note that we added the peer group's food preference to the diets of women with zero consumption of a food group, assuming that, given sufficient resources, women 
Table 6 Dietary modelling of food additions using Method A, women's personal food preferences, adjusted and unadjusted for food insecurity with hunger $(n=226)$

\begin{tabular}{|c|c|c|c|c|c|}
\hline \multirow[b]{2}{*}{ Nutrient } & \multirow[b]{2}{*}{$\begin{array}{l}\text { Requirement, } \\
\text { EAR } \pm \text { SD } \\
\text { + serving }\end{array}$} & \multicolumn{2}{|c|}{$\begin{array}{l}\text { Unadjusted for food insecurity } \\
\text { with hunger }\end{array}$} & \multicolumn{2}{|c|}{$\begin{array}{l}\text { Adjusted for food insecurity } \\
\text { with hunger }\end{array}$} \\
\hline & & $\begin{array}{c}\text { Estimated usual } \\
\text { intake, mean } \pm \mathrm{SD} \\
\text { (median) }\end{array}$ & $\begin{array}{l}\text { Prevalence of } \\
\text { inadequacy (\%) }\end{array}$ & $\begin{array}{c}\text { Estimated usual } \\
\text { intake, mean } \pm S D \\
\text { (median) }\end{array}$ & $\begin{array}{l}\text { Prevalence of } \\
\text { inadequacy (\%) }\end{array}$ \\
\hline \multirow[t]{5}{*}{ Calcium $\left(\mathrm{mg} \mathrm{day}^{-1}\right)$} & $A I=1000$ & $637 \pm 325(578)$ & & $673 \pm 325(578)$ & \\
\hline & +1 fruit & $654 \pm 326(595)$ & & $694 \pm 338(634)$ & \\
\hline & +1 vegetable & $652 \pm 325(593)$ & & $690 \pm 336(630)$ & \\
\hline & +1 milk & $1021 \pm 452(931)$ & & $1091 \pm 480(995)$ & \\
\hline & $+1 \mathrm{f} \& 1 \mathrm{v} \& 1 \mathrm{~m}$ & $1054 \pm 450(964)$ & & $1134 \pm 494(1035)$ & \\
\hline \multirow[t]{5}{*}{ Iron (mg day ${ }^{-1}$ ) } & $8.1 \pm 4.95$ & $10.8 \pm 3.8$ & $37.4 / 17.6$ (no OC/OC) & $11.2 \pm 3.9$ & $34.2 / 14.9$ (no OC/OC) \\
\hline & +1 fruit & $11.2 \pm 3.8$ & $33.9 / 14.4$ & $11.7 \pm 4.0$ & $30.7 / 12.3$ \\
\hline & +1 vegetable & $11.5 \pm 3.79$ & $31.0 / 12.0$ & $12.0 \pm 3.8$ & 27.7/9.6 \\
\hline & +1 milk & $11.0 \pm 3.7$ & $35.3 / 15.5$ & $11.5 \pm 3.9$ & $32.2 / 13.3$ \\
\hline & $+1 \mathrm{f} \& 1 \mathrm{v} \& 1 \mathrm{~m}$ & $12.1 \pm 3.7$ & $26.7 / 9.0$ & $12.6 \pm 3.9$ & $23.4 / 6.9$ \\
\hline \multirow[t]{5}{*}{ Magnesium (mg day ${ }^{-1}$ ) } & $255 \pm 27.5$ & $231.2 \pm 81.6$ & 72.4 & $244.1 \pm 85.3$ & 67.1 \\
\hline & +1 fruit & $246.2 \pm 82.4$ & 66.1 & $263 \pm 88.3$ & 58.7 \\
\hline & +1 vegetable & $246.8 \pm 79.4$ & 66.2 & $261 \pm 83.0$ & 59.4 \\
\hline & +1 milk & $264.6 \pm 81.6$ & 55.7 & $280 \pm 85.6$ & 47.6 \\
\hline & $+1 \mathrm{f} \& 1 \mathrm{v} \& 1 \mathrm{~m}$ & $295.5 \pm 81.7$ & 40.7 & $315.9 \pm 88.1$ & 31.5 \\
\hline \multirow{5}{*}{ Niacin $\left(\mathrm{mg} \mathrm{day}^{-1}\right)$} & $11 \pm 1.5$ & $27.6 \pm 8.8$ & 15.0 & $29.1 \pm 9.0$ & 8.8 \\
\hline & +1 fruit & $28.1 \pm 8.9$ & 11.2 & $29.7 \pm 8.9$ & 6.5 \\
\hline & +1 vegetable & $28.8 \pm 8.8$ & 7.4 & $30.4 \pm 9.0$ & 3.8 \\
\hline & +1 milk & $30.4 \pm 8.9$ & 3.5 & $32.2 \pm 9.1$ & 2.2 \\
\hline & $+1 \mathrm{f} \& 1 \mathrm{v} \& 1 \mathrm{~m}$ & $32.1 \pm 8.9$ & 0.7 & $34.1 \pm 9.1$ & 0.3 \\
\hline \multirow[t]{5}{*}{ Riboflavin (mg day ${ }^{-1}$ ) } & $0.9 \pm 0.1$ & $1.44 \pm 0.58$ & 20.0 & $1.51 \pm 0.59$ & 16.3 \\
\hline & +1 fruit & $1.48 \pm 0.56$ & 16.1 & $1.57 \pm 0.58$ & 12.3 \\
\hline & +1 vegetable & $1.48 \pm 0.56$ & 16.5 & $1.56 \pm 0.57$ & 12.7 \\
\hline & +1 milk & $1.87 \pm 0.63$ & 4.3 & $1.98 \pm 0.66$ & 2.7 \\
\hline & $+1 \mathrm{f} \& 1 \mathrm{v} \& 1 \mathrm{~m}$ & $1.96 \pm 0.64$ & 2.7 & $2.09 \pm 0.67$ & 1.5 \\
\hline \multirow[t]{5}{*}{ Thiamin $\left(\mathrm{mg} \mathrm{day}^{-1}\right)$} & $0.9 \pm 0.1$ & $1.03 \pm 0.36$ & 42.8 & $1.08 \pm 0.38$ & 38.1 \\
\hline & +1 fruit & $1.09 \pm 0.37$ & 35.7 & $1.16 \pm 0.40$ & 29.9 \\
\hline & +1 vegetable & $1.09 \pm 0.36$ & 36.1 & $1.15 \pm 0.38$ & 30.8 \\
\hline & +1 milk & $1.12 \pm 0.36$ & 31.3 & $1.18 \pm 0.38$ & 26.4 \\
\hline & $+1 f \& 1 v \& 1 m$ & $1.25 \pm 0.37$ & 19.1 & $1.33 \pm 0.40$ & 14.2 \\
\hline \multirow[t]{5}{*}{ Vitamin $B_{12}\left(\mu\right.$ day $\left.^{-1}\right)$} & $2.0 \pm 0.2$ & $4.19 \pm 3.64$ & 27.1 & $4.42 \pm 3.66$ & 21.8 \\
\hline & +1 fruit & $4.19 \pm 3.64$ & 27.1 & $4.42 \pm 3.66$ & 21.8 \\
\hline & +1 vegetable & $4.20 \pm 3.63$ & 27.0 & $4.42 \pm 3.65$ & 21.7 \\
\hline & +1 milk & $5.07 \pm 3.84$ & 8.8 & $5.40 \pm 3.90$ & 5.7 \\
\hline & $+1 \mathrm{f} \& 1 \mathrm{v} \& 1 \mathrm{~m}$ & $5.07 \pm 3.82$ & 8.8 & $5.41 \pm 3.08$ & 5.6 \\
\hline \multirow[t]{5}{*}{ Vitamin A (RAE day $\left.{ }^{-1}\right)$} & $500 \pm 100$ & $730 \pm 543$ & 46.9 & $766 \pm 544$ & 42.3 \\
\hline & +1 fruit & $748 \pm 568$ & 44.7 & $788 \pm 571$ & 40.1 \\
\hline & +1 vegetable & $794 \pm 570$ & 38.7 & $828 \pm 545$ & 33.8 \\
\hline & +1 milk & $869 \pm 569$ & 27.9 & $918 \pm 566$ & 22.9 \\
\hline & $+1 \mathrm{f} \& 1 \mathrm{v} \& 1 \mathrm{~m}$ & $955 \pm 580$ & 20.0 & $1014 \pm 581$ & 15.5 \\
\hline \multirow[t]{5}{*}{ Vitamin C $\left(\mathrm{mg} \mathrm{day}^{-1}\right)$} & $60 \pm 7.5 / 95 \pm 9.5^{\star}$ & $96.3 \pm 57.3$ & 43.8 & $110.0 \pm 68.7$ & 38.3 \\
\hline & +1 fruit & $127.3 \pm 60.3$ & 24.9 & $147.5 \pm 77.7$ & 21.2 \\
\hline & +1 vegetable & $109.9 \pm 60.9$ & 35.8 & $125.3 \pm 73.0$ & 31.1 \\
\hline & +1 milk & $101.4 \pm 58.0$ & 39.4 & $115.7 \pm 69.0$ & 34.7 \\
\hline & $+1 \mathrm{f} \& 1 \mathrm{v} \& 1 \mathrm{~m}$ & $146.1 \pm 64.8$ & 14.9 & $168.1 \pm 82.5$ & 12.7 \\
\hline \multirow[t]{5}{*}{ Vitamin $\mathrm{B}_{6}\left(\mathrm{mg} \mathrm{day}^{-1}\right)$} & $1.1 \pm 0.1$ & $1.34 \pm 0.48$ & 41.9 & $1.44 \pm 0.50$ & 33.9 \\
\hline & +1 fruit & $1.51 \pm 0.53$ & 30.1 & $1.65 \pm 0.59$ & 23.5 \\
\hline & +1 vegetable & $1.48 \pm 0.47$ & 28.6 & $1.60 \pm 0.49$ & 20.1 \\
\hline & +1 milk & $1.44 \pm 0.48$ & 31.7 & $1.55 \pm 0.50$ & 23.6 \\
\hline & $+1 f \& 1 v \& 1 m$ & $1.75 \pm 0.51$ & 10.8 & $1.92 \pm 0.57$ & 6.3 \\
\hline \multirow[t]{5}{*}{ Zinc (mg day ${ }^{-1}$ ) } & $6.8 \pm 0.6$ & $9.02 \pm 3.29$ & 32.7 & $9.52 \pm 3.37$ & 27.0 \\
\hline & +1 fruit & $9.11 \pm 3.25$ & 31.1 & $9.65 \pm 3.38$ & 25.5 \\
\hline & +1 vegetable & $9.28 \pm 3.24$ & 29.3 & $9.80 \pm 3.31$ & 23.2 \\
\hline & +1 milk & $10.33 \pm 3.29$ & 17.4 & $10.94 \pm 3.31$ & 12.1 \\
\hline & $+1 f \& 1 v \& 1 m$ & $10.70 \pm 3.27$ & 13.3 & $11.36 \pm 3.35$ & 8.6 \\
\hline Energy (kJ day ${ }^{-1}$ ) & & $7252 \pm 2504$ & $\mathrm{Q} 3=8453 \dagger$ & $7536 \pm 2550$ & $\mathrm{Q} 3=8453 \dagger$ \\
\hline & +1 fruit & $7557 \pm 2516$ & $=8742$ & $7917 \pm 2592$ & $=9186$ \\
\hline & +1 vegetable & $7494 \pm 2491$ & $=8709$ & $7804 \pm 2533$ & $=8993$ \\
\hline & +1 milk & $8060 \pm 2554$ & $=9215$ & $8416 \pm 2613$ & $=9713$ \\
\hline & $+1 \mathrm{f} \& 1 \mathrm{v} \& 1 \mathrm{~m}$ & $8621 \pm 2554$ & $=9730$ & $9069 \pm 2646$ & $=10295$ \\
\hline
\end{tabular}

EAR - Estimated Average Requirement; SD - standard deviation; RAE - retinol activity equivalents; Al - Adequate Intake; OC - oral contraceptives. ${ }^{*}$ Requirements for non-smokers/smokers ${ }^{41}$.

†75th percentile of energy intakes. 
Table 7 Dietary modelling of food additions using Method B, food preferences for the population, adjusted and unadjusted for food insecurity with hunger $(n=226)$

\begin{tabular}{|c|c|c|c|c|c|}
\hline \multirow[b]{2}{*}{ Nutrient } & \multirow[b]{2}{*}{$\begin{array}{l}\text { Requirement, } \\
\text { EAR } \pm \text { SD } \\
+ \text { serving }\end{array}$} & \multicolumn{2}{|c|}{ Unadjusted for food insecurity with hunger } & \multicolumn{2}{|c|}{ Adjusted for food insecurity with hunger } \\
\hline & & $\begin{array}{l}\text { Estimated usual } \\
\text { intake, mean } \pm \text { SD } \\
\text { (median) }\end{array}$ & $\begin{array}{l}\text { Prevalence of } \\
\text { inadequacy (\%) }\end{array}$ & $\begin{array}{l}\text { Estimated usual intake, } \\
\text { mean } \pm S D \\
\text { (median) }\end{array}$ & $\begin{array}{l}\text { Prevalence of } \\
\text { inadequacy (\%) }\end{array}$ \\
\hline \multirow[t]{5}{*}{ Calcium (mg day ${ }^{-1}$ ) } & $A I=1000$ & $637 \pm 325(578)$ & & $673 \pm 325(578)$ & \\
\hline & +1 fruit & $648 \pm 325$ (589) & & $684 \pm 336(624)$ & \\
\hline & +1 vegetable & $643 \pm 325(584)$ & & $679 \pm 335(620)$ & \\
\hline & +1 milk & $951 \pm 337(885)$ & & $987 \pm 347(921)$ & \\
\hline & $+1 \mathrm{f} \& 1 \mathrm{v} \& 1 \mathrm{~m}$ & $970 \pm 337$ (903) & & $1006 \pm 347$ (939) & \\
\hline \multirow[t]{5}{*}{ Iron $\left(\mathrm{mg} \mathrm{day}^{-1}\right)$} & $8.1 \pm 4.95$ & $10.8 \pm 3.8$ & 37.4/17.6 (no OC/OC) & $11.2 \pm 3.9$ & 34.2/14.9 (no OC/OC) \\
\hline & +1 fruit & $10.9 \pm 3.7$ & $35.9 / 16.1$ & $11.4 \pm 3.9$ & 33.0/13.6 \\
\hline & +1 vegetable & $11.1 \pm 3.8$ & $34.9 / 15.1$ & $11.5 \pm 3.9$ & $31.4 / 13.0$ \\
\hline & +1 milk & $10.9 \pm 3.8$ & $36.0 / 16.1$ & $11.4 \pm 3.9$ & $33.0 / 13.6$ \\
\hline & $+1 \mathrm{f} \& 1 \mathrm{v} \& 1 \mathrm{~m}$ & $11.3 \pm 3.7$ & $32.3 / 13.0$ & $11.7 \pm 3.8$ & 29.4/11.0 \\
\hline \multirow[t]{5}{*}{ Magnesium (mg day ${ }^{-1}$ ) } & $255 \pm 27.5$ & $231.2 \pm 81.6$ & 72.4 & $244.1 \pm 85.3$ & 67.1 \\
\hline & +1 fruit & $244.2 \pm 81.0$ & 66.9 & $257.2 \pm 84.7$ & 61.0 \\
\hline & +1 vegetable & $247.5 \pm 81.1$ & 65.5 & $260.0 \pm 84.6$ & 59.5 \\
\hline & +1 milk & $266.4 \pm 81.2$ & 65.6 & $279.3 \pm 84.8$ & 50.1 \\
\hline & $+1 \mathrm{f} \& 1 \mathrm{v} \& 1 \mathrm{~m}$ & $296.0 \pm 81.3$ & 41.2 & $309.0 \pm 85.0$ & 35.3 \\
\hline \multirow[t]{5}{*}{ Niacin $\left(\mathrm{mg} \mathrm{day}^{-1}\right)$} & $11 \pm 1.5$ & $27.6 \pm 8.8$ & 15.0 & $29.1 \pm 9.0$ & 8.8 \\
\hline & +1 fruit & $27.9 \pm 8.8$ & 12.3 & $29.4 \pm 9.0$ & 7.1 \\
\hline & +1 vegetable & $29.0 \pm 8.9$ & 5.8 & $30.6 \pm 9.1$ & 3.5 \\
\hline & +1 milk & $29.8 \pm 8.9$ & 3.2 & $31.4 \pm 9.1$ & 1.8 \\
\hline & $+1 \mathrm{f} \& 1 \mathrm{v} \& 1 \mathrm{~m}$ & $31.6 \pm 8.9$ & 0.6 & $33.1 \pm 9.1$ & 0.2 \\
\hline \multirow[t]{5}{*}{ Riboflavin (mg day ${ }^{-1}$ ) } & $0.9 \pm 0.1$ & $1.44 \pm 0.58$ & 20.0 & $1.51 \pm 0.59$ & 16.3 \\
\hline & +1 fruit & $1.46 \pm 0.57$ & 17.8 & $1.53 \pm 0.58$ & 14.2 \\
\hline & +1 vegetable & $1.45 \pm 0.57$ & 18.3 & $1.53 \pm 0.58$ & 14.7 \\
\hline & +1 milk & $1.85 \pm 0.56$ & 1.6 & $1.93 \pm 0.57$ & 1.1 \\
\hline & $+1 \mathrm{f} \& 1 \mathrm{v} \& 1 \mathrm{~m}$ & $1.89 \pm 0.56$ & 1.0 & $1.97 \pm 0.57$ & 0.7 \\
\hline \multirow{5}{*}{ Thiamin $\left(\mathrm{mg} \mathrm{day}^{-1}\right)$} & $0.9 \pm 0.1$ & $1.03 \pm 0.36$ & 42.8 & $1.08 \pm 0.38$ & 38.1 \\
\hline & +1 fruit & $1.13 \pm 0.36$ & 31.3 & $1.18 \pm 0.38$ & 26.8 \\
\hline & +1 vegetable & $1.11 \pm 0.36$ & 34.0 & $1.16 \pm 0.38$ & 29.4 \\
\hline & +1 milk & $1.13 \pm 0.36$ & 31.8 & $1.18 \pm 0.38$ & 27.3 \\
\hline & $+1 \mathrm{f} \& 1 \mathrm{v} \& 1 \mathrm{~m}$ & $1.31 \pm 0.36$ & 13.6 & $1.36 \pm 0.38$ & 11.0 \\
\hline \multirow{5}{*}{ Vitamin $B_{12}\left(\mu\right.$ g day $\left.^{-1}\right)$} & $2.0 \pm 0.2$ & $4.19 \pm 3.64$ & 27.1 & $4.42 \pm 3.66$ & 21.8 \\
\hline & +1 fruit & $4.19 \pm 3.64$ & 27.1 & $4.42 \pm 3.66$ & 21.8 \\
\hline & +1 vegetable & $4.19 \pm 3.64$ & 27.1 & $4.42 \pm 3.66$ & 21.8 \\
\hline & +1 milk & $5.12 \pm 3.69$ & 3.2 & $5.36 \pm 3.76$ & 2.4 \\
\hline & $+1 \mathrm{f} \& 1 \mathrm{v} \& 1 \mathrm{~m}$ & $5.12 \pm 3.69$ & 3.2 & $5.36 \pm 3.76$ & 2.4 \\
\hline \multirow{5}{*}{ Vitamin A (RAE day $\left.{ }^{-1}\right)$} & $500 \pm 100$ & $730 \pm 543$ & 46.9 & $766 \pm 544$ & 42.3 \\
\hline & +1 fruit & $724 \pm 513$ & 45.1 & $758 \pm 510$ & 40.7 \\
\hline & +1 vegetable & $730 \pm 543$ & 46.9 & $766 \pm 544$ & 42.3 \\
\hline & +1 milk & $904 \pm 630$ & 25.7 & $940 \pm 626$ & 22.0 \\
\hline & $+1 \mathrm{f} \& 1 \mathrm{v} \& 1 \mathrm{~m}$ & $911 \pm 630$ & 24.8 & $947 \pm 626$ & 21.2 \\
\hline \multirow[t]{5}{*}{ Vitamin C $\left(\mathrm{mg} \mathrm{day}^{-1}\right)$} & $60 \pm 7.5 / 95 \pm 9.5^{*}$ & $96.3 \pm 57.3$ & 43.8 & $110.0 \pm 68.7$ & 38.3 \\
\hline & +1 fruit & $148.9 \pm 59.9$ & 11.7 & $162.0 \pm 69.9$ & 10.0 \\
\hline & +1 vegetable & $102.7 \pm 58.4$ & 39.7 & $116.7 \pm 69.5$ & 35.1 \\
\hline & +1 milk & $99.3 \pm 60.3$ & 42.4 & $113.6 \pm 72.2$ & 37.3 \\
\hline & $+1 \mathrm{f} \& 1 \mathrm{v} \& 1 \mathrm{~m}$ & $156.4 \pm 58.5$ & 8.6 & $170.9 \pm 70.0$ & 7.3 \\
\hline \multirow{5}{*}{ Vitamin $\mathrm{B}_{6}\left(\mathrm{mg} \mathrm{day}^{-1}\right)$} & $1.1 \pm 0.1$ & $1.34 \pm 0.48$ & 41.9 & $1.44 \pm 0.50$ & 33.9 \\
\hline & +1 fruit & $1.39 \pm 0.48$ & 36.9 & $1.50 \pm 0.50$ & 29.2 \\
\hline & +1 vegetable & $1.56 \pm 0.49$ & 22.5 & $1.66 \pm 0.51$ & 16.3 \\
\hline & +1 milk & $1.45 \pm 0.49$ & 32.2 & $1.55 \pm 0.51$ & 24.9 \\
\hline & $+1 \mathrm{f} \& 1 \mathrm{v} \& 1 \mathrm{~m}$ & $1.72 \pm 0.49$ & 10.9 & $1.83 \pm 0.51$ & 6.9 \\
\hline \multirow[t]{5}{*}{ Zinc $\left(\mathrm{mg} \mathrm{day}^{-1}\right)$} & $6.8 \pm 0.6$ & $9.02 \pm 3.29$ & 32.7 & $9.52 \pm 3.37$ & 27.0 \\
\hline & +1 fruit & $9.07 \pm 3.25$ & 31.5 & $9.59 \pm 3.37$ & 26.3 \\
\hline & +1 vegetable & $9.23 \pm 3.26$ & 29.8 & $9.73 \pm 3.34$ & 24.2 \\
\hline & +1 milk & $10.02 \pm 3.29$ & 21.0 & $10.5 \pm 3.4$ & 16.0 \\
\hline & $+1 \mathrm{f} \& 1 \mathrm{v} \& 1 \mathrm{~m}$ & $10.31 \pm 3.30$ & 17.6 & $10.8 \pm 3.4$ & 13.2 \\
\hline Energy $\left(\mathrm{kJ} \mathrm{day}^{-1}\right)$ & & $7252 \pm 2504$ & Q3 = 8453† & $7536 \pm 2550$ & Q3 = 8696† \\
\hline & +1 fruit & $7494 \pm 2504$ & $=8704$ & $7783 \pm 2546$ & $=8951$ \\
\hline & +1 vegetable & $7540 \pm 2504$ & $=8750$ & $7829 \pm 2546$ & $=8993$ \\
\hline & +1 milk & $7779 \pm 2500$ & $=8993$ & $8068 \pm 2546$ & $=9232$ \\
\hline & +1f\&1v\&1m & $8323 \pm 2500$ & $=9538$ & $8612 \pm 2546$ & $=9776$ \\
\hline
\end{tabular}

EAR - Estimated Average Requirement; SD - standard deviation; RAE - retinol activity equivalents; AI - Adequate Intake; OC - oral contraceptives. ${ }^{*}$ Requirements for non-smokers/smokers ${ }^{41}$. †75th percentile of energy intakes. 
Table 8 Highest nutritional impact achieved by adding women's personal food preferences after alleviating food insecurity with hunger state $(n=226)^{\star}$

\begin{tabular}{|c|c|c|c|c|}
\hline Nutrient & $\begin{array}{c}\text { Requirement, } \\
\text { EAR } \pm \text { SD } \\
\text { + serving }\end{array}$ & $\begin{array}{l}\text { Estimated usual intake, } \\
\text { mean } \pm \mathrm{SD} \text { (median) }\end{array}$ & $\begin{array}{l}\text { Prevalence of } \\
\text { inadequacy }(\%)\end{array}$ & $\begin{array}{l}\text { Comments re. dietary goal of } \\
2-3 \% \text { prevalence of inadequacy }\end{array}$ \\
\hline \multirow[t]{2}{*}{ Calcium (mg day ${ }^{-1}$ ) } & $\mathrm{Al}=\mathbf{1 0 0 0}$ & $673 \pm 325(578)$ & & Intake achieved \\
\hline & +1 milk & $1091 \pm 480(995)$ & & Inadequacy persists for non-OC users (32\% reduction); \\
\hline \multirow[t]{2}{*}{ Iron (mg day ${ }^{-1}$ ) } & $8.1 \pm 4.95$ & $11.2 \pm 3.9$ & $34.2 / 14.9$ (no OC/OC) & 3 servings yield $54 \%$ reduction for OC users \\
\hline & $+1 \mathrm{f} \& 1 \mathrm{v} \& 1 \mathrm{~m}$ & $12.6 \pm 3.9$ & $23.4 / 6.9$ & \\
\hline \multirow[t]{2}{*}{ Magnesium $\left(\mathrm{mg} \mathrm{day}^{-1}\right)$} & $255 \pm 27.5$ & $244.1 \pm 85.3$ & 67.1 & Inadequacy persists; 3 servings yield $53 \%$ reduction \\
\hline & $+1 \mathrm{f} \& 1 \mathrm{v} \& 1 \mathrm{~m}$ & $315.9 \pm 88.1$ & 31.5 & \\
\hline \multirow[t]{2}{*}{ Niacin $\left(\mathrm{mg} \mathrm{day}^{-1}\right)$} & $11 \pm 1.5$ & $29.1 \pm 9.0$ & 8.8 & Achieved \\
\hline & +1 milk & $32.2 \pm 9.1$ & 2.2 & \\
\hline \multirow[t]{2}{*}{ Riboflavin $\left(\mathrm{mg} \mathrm{day}^{-1}\right.$ ) } & $0.9 \pm 0.1$ & $1.51 \pm 0.59$ & 16.3 & Achieved \\
\hline & +1 milk & $1.98 \pm 0.66$ & 2.7 & \\
\hline \multirow[t]{2}{*}{ Thiamin $\left(\mathrm{mg} \mathrm{day}^{-1}\right)$} & $0.9 \pm 0.1$ & $1.08 \pm 0.38$ & 38.1 & 3 servings yield $63 \%$ reduction \\
\hline & $+1 \mathrm{f} \& 1 \mathrm{v} \& 1 \mathrm{~m}$ & $1.33 \pm 0.40$ & 14.2 & \\
\hline \multirow[t]{2}{*}{ Vitamin $B_{12}\left(\mu \mathrm{g} \mathrm{day}^{-1}\right)$} & $2.0 \pm 0.2$ & $4.42 \pm 3.66$ & 21.8 & 1 milk serving yields $74 \%$ reduction \\
\hline & +1 milk & $5.40 \pm 3.90$ & 5.7 & \\
\hline \multirow[t]{2}{*}{ Vitamin A (RAE day ${ }^{-1}$ ) } & $500 \pm 100$ & $766 \pm 544$ & 42.3 & 3 servings yield $63 \%$ reduction \\
\hline & $+1 \mathrm{f} \& 1 \mathrm{v} \& 1 \mathrm{~m}$ & $1014 \pm 581$ & 15.5 & \\
\hline \multirow[t]{2}{*}{ Vitamin C $\left(\mathrm{mg} \mathrm{day}^{-1}\right)$} & $60 \pm 7.5 / 95 \pm 9.5 \dagger$ & $110.0 \pm 68.7$ & 38.3 & 3 servings yield $67 \%$ reduction \\
\hline & $+1 \mathrm{f} \& 1 \mathrm{v} \& 1 \mathrm{~m}$ & $168.1 \pm 82.5$ & 12.7 & \\
\hline \multirow[t]{2}{*}{ Vitamin $\mathrm{B}_{6}\left(\mathrm{mg} \mathrm{day}^{-1}\right)$} & $1.1 \pm 0.1$ & $1.44 \pm 0.50$ & 33.9 & 3 servings yield $81 \%$ reduction \\
\hline & $+1 \mathrm{f} \& 1 \mathrm{v} \& 1 \mathrm{~m}$ & $1.92 \pm 0.57$ & 6.3 & \\
\hline \multirow[t]{2}{*}{ Zinc (mg day ${ }^{-1}$ ) } & $6.8 \pm 0.6$ & $9.52 \pm 3.37$ & 27.0 & 3 servings yield $68 \%$ reduction \\
\hline & $+1 \mathrm{f} \& 1 \mathrm{v} \& 1 \mathrm{~m}$ & $11.36 \pm 3.35$ & 8.6 & \\
\hline
\end{tabular}

EAR - Estimated Average Requirement; SD - standard deviation; RAE - retinol activity equivalents; AI - Adequate Intake; OC - oral contraceptives. ${ }^{*}$ Compared with baseline, addition of one serving of fruit (1f), vegetable (1v) and/or milk (1m). †Requirements for non-smokers/smokers ${ }^{41}$.

would consume foods similar to their peers. Ultimately, however, we do not know how any of the women in this sample would adjust their food intakes in response to improved access to specific foods, whether these are drawn from their own dietary records or those of their peers. A demonstration project in which low-income, food-insecure women are provided with improved access to specific nutritious foods of their preference is required to gain insight into these questions.

\section{Conclusions}

Food-insecure women would sustain substantive nutritional gains if they had greater access to their personal 'healthy' food preferences and if states of severe food insecurity were abated. Increased resources to access such choices should be a priority, following which attention could be paid to other dietary quality improvements that could reduce the prevalence of inadequacy in this population to an acceptably low level (e.g. $2-3 \%$ ).

\section{Acknowledgements}

Sources of funding: This study was funded by the CIHRNSHRF-Dairy Farmers of Canada regional partnership programme, grant no. 62216.

Conflict of interest declaration: None.

Authorship responsibilities: L. M. and V. T. were equally responsible for study design, data interpretation and manuscript preparation. T. J. L. was primarily responsible for data analysis.

Acknowledgements: We are indebted to Mark Nord for assistance with the food insecurity analysis.

\section{References}

1 Rainville B, Brink S. Food Insecurity in Canada, 1998-1999. Ottawa: Human Resources Development Canada, Applied Research Branch of Strategic Policy, 2001.

2 McIntyre L, Connor SK, Warren J. Child hunger in Canada: results of the 1994 National Longitudinal Survey of Children and Youth. Canadian Medical Association Journal 2000; 163(8): 961-5.

3 McIntyre L, Glanville NT, Officer S, Anderson B, Raine KD, Dayle JB. Food insecurity of low-income lone mothers and their children in Atlantic Canada. Canadian Journal of Public Health 2002; 93(6): 411-5.

4 McIntyre L, Glanville NT, Raine KD, Dayle JB, Anderson B, Battaglia N. Do low-income lone mothers compromise their nutrition to feed their children? Canadian Medical Association Journal 2003; 168(6): 686-91.

5 Tarasuk VS, Beaton GH. Women's dietary intakes in the context of household food insecurity. Journal of Nutrition 1999; 129(3): 672-9.

6 Tarasuk VS. Household food insecurity with hunger is associated with women's food intakes, health and household circumstances. Journal of Nutrition 2001; 131(10): 2670-6.

7 Tarasuk V. Low income, welfare and nutritional vulnerability. Canadian Medical Association Journal 2003; 168(6): 709-10.

8 Badun C, Evers S, Hooper M. Food security and nutritional concerns of parents in an economically disadvantaged community. Journal of the Canadian Dietetic Association 1995; 56(2): 75-80. 
9 Hamelin AM, Beaudry M, Habicht JP. Characterization of household food insecurity in Quebec: food and feelings. Social Science \& Medicine 2002; 54(1): 119-32.

10 McIntyre L, Officer S, Robinson L. Feeling poor: the felt experience of low-income lone mothers. Affilia 2003; 18(3): $316-31$.

11 McIntyre L, Travers K, Dayle JB. Children's feeding programs in Atlantic Canada: reducing or reproducing inequities? Canadian Journal of Public Health 1999; 90(3): 196-200.

12 Edward HG, Evers S. Benefits and barriers associated with participation in food programs in three low-income Ontario communities. Canadian Journal of Dietetic Practice and Research 2001; 62(2): 76-81.

13 Tarasuk V. A critical examination of community-based responses to household food insecurity in Canada. Health Education \& Behavior 2001; 28(4): 487-99.

14 Jacobs Starkey L, Kuhnlein HV, Gray-Donald K. Food bank users: sociodemographic and nutritional characteristics. Canadian Medical Association Journal 1998; 158(9): 1143-9.

15 Tarasuk V, Reynolds R. A qualitative study of community kitchens as a response to income-related food insecurity. Canadian Journal of Dietetic Practice and Research 1999; 60(1): 11-6.

16 Crawford S, Kalina L. Building food security through health promotion: community kitchens. Journal of the Canadian Dietetic Association 1997; 58(4): 197-201.

17 Kalina L. Building Food Security in Canada: From Hunger to Sustainable Food Systems: A Community Guide, 2nd ed. Kamloops: Kamloops FoodShare, 2001.

18 McLaughlin C, Tarasuk V, Kreiger N. An examination of at-home food preparation activity among low-income, food-insecure women. Journal of the American Dietetic Association 2003; 103(11): 1506-12.

19 Travers K. 'Do you teach them how to budget?': professional discourse in the construction of nutritional inequities. In: Maurer D, Sobal J, eds. Eating Agendas. Hawthorne, NY: Aldine DeGruyter, 1995; 213-40.

20 Fano TJ, Tyminski SM, Flynn MA. Evaluation of a collective kitchens program: using the Population Health Promotion Model. Canadian Journal of Dietetic Practice and Research 2004; 65(2): 72-80.

21 Engler-Stringer R, Berenbaum S. Collective kitchens in Canada: a review of the literature. Canadian Journal of Dietetic Practice and Research 2005; 66(4): 246-51.

22 Welsh J, MacRae R. Food citizenship and community food security: lessons from Toronto, Canada. Canadian Journal of Development Studies 1998; XIX: 237-55.

23 Food and Hunger Action Committee. Planting the Seeds: Phase I Report. Toronto: Food and Hunger Action Committee, May 2000.

24 Institute of Medicine. Dietary Reference Intakes: Applications in Dietary Planning. Washington, DC: National Academy Press, 2003.

25 Tarasuk VS, Beaton GH. Household food insecurity and hunger among families using food banks. Canadian Journal of Public Health 1999; 90(2): 109-13.

26 Kendall A, Olson CM, Frongillo EA Jr. Validation of the Radimer/Cornell measures of hunger and food insecurity. Journal of Nutrition 1995; 125(11): 2793-801.

27 Radimer KL, Olson CM, Greene JC, Campbell CC, Habicht JP. Understanding hunger and developing indicators to assess it in women and children. Journal of Nutrition Education 1992; 24(1): 36S-45S.

28 Hamelin AM, Habicht JP, Beaudry M. Food insecurity: consequences for the household and broader social implications. Journal of Nutrition 1999; 129(2S Suppl.): 525S-8S.

29 Hamilton W, Cook J, Thompson WW, Buron LF, Frongillo EA Jr, Olson CM, et al. Household Food Security in the United States in 1995. Summary Report of the Food Security Measurement Project. Alexandria, VA: US Department of
Agriculture/Food and Consumer Service/Office of Analysis and Evaluation, 1997.

30 Institute of Medicine. Dietary Reference Intakes: Vitamin A, Vitamin K, Arsenic, Boron, Chromium, Copper, Iodine, Iron, Manganese, Molybdenum, Nickel, Silicon, Vanadium, and Zinc. Washington, DC: National Academy Press, 2001

31 Health Canada. Canada's Food Guide to Healthy Eating. Ottawa: Minister of Public Works and Government Services Canada, 1997.

32 US Department of Agriculture (USDA). National Nutrient Database for Standard Reference. Washington, DC: USDA, 2004.

33 Bond T, Fox C, eds. Applying the Rasch Model: Fundamental Measurement in the Human Sciences. Mahway, NJ: Lawrence Erlbaum Associates, 2001.

34 Nord M, Tarasuk V, McIntyre L, Tagtow A, Radimer K. Comparing prevalence rates of food insecurity based on Radimer/Cornell measures and the US Household Food Security Scale. Presented at Annual Meeting of the National Association for Welfare Research and Statistics, San Diego, CA, 13-16 July 2003.

35 Nord M, Fogarty D. Comparing prevalence rates of food insecurity and hunger based on non-standard question sets to the national benchmark. Presented at Fourth International Conference on Dietary Assessment Methods, Tucson, AZ, 17-20 September 2000.

36 Institute of Medicine. Dietary Reference Intakes: Applications in Dietary Assessment. Washington DC: National Academy Press, 2000.

37 Department of Statistics and Center for Agricultural and Rural Development IS. A User's Guide to SIDE (Software for Intake Distribution Estimation), Version 1.O. Ames, IA: Iowa State University, 1996.

38 McIntyre L, Raine K, Glanville N, Dayle J. Hungry Mothers of Barely Fed Children: A Study of the Diets and Food Experiences of Low-income Lone Mothers in Atlantic Canada. Final Report to the Canadian Institutes of Health Research (CIHR)/National Health Research and Development Program (NHRDP). Ottawa: CIHR/NHRDP, March 2001.

39 Institute of Medicine. Dietary Reference Intakes for Calcium, Phosphorus, Magnesium, Vitamin D, and Fluoride. Washington, DC: National Academy Press, 1997.

40 Institute of Medicine. Dietary Reference Intakes for Thiamin, Riboflavin, Niacin, Vitamin $B_{6}$, Folate, Vitamin $B_{12}$, Pantothenic Acid, Biotin, and Choline. Washington, DC: National Academy Press, 1998.

41 Institute of Medicine. Dietary Reference Intakes for Vitamin C, Vitamin E, Selenium, and Carotenoids. Washington, DC: National Academy Press, 2000.

42 Kirkpatrick S, Tarasuk V. The relationship between low income and household food expenditure patterns in Canada. Public Health Nutrition 2003; 6(6): 589-97.

43 Ricciuto L, Tarasuk V, Yatchew A. Socio-demographic influences on food purchasing among Canadian households. European Journal of Clinical Nutrition 2006; 60(6): $778-90$.

44 Garriguet D. Nutrition: Findings from the Canadian Community Health Survey. Overview of Canadians' Eating Habits 2004. Ottawa: Statistics Canada/Ministry of Industry, 2006.

45 Vozoris N, Davis B, Tarasuk V. The affordability of a nutritious diet for households on welfare in Toronto. Canadian Journal of Public Health 2002; 93(1): 36-40.

46 Power E. Individual and Household Food Insecurity in Canada: Position of the Dietitians of Canada. Toronto: Dietitians of Canada, 2005.

47 Williams PL, Johnson CP, Kratzmann ML, Johnson CS, Anderson BJ, Chenhall C. Can households earning minimum wage in Nova Scotia afford a nutritious diet? Canadian Journal of Public Health 2006; 97(6): 430-4. 